\title{
Efeito de sistemas de manejo do solo e velocidade de semeadura no desenvolvimento do sorgo forrageiro
}

\author{
Flávia Meinicke Nascimento ${ }^{1}$, José Guilherme Lança Rodrigues ${ }^{2}$, Jairo Costa Fernandes ${ }^{3}$, \\ Carlos Antonio Gamero ${ }^{4}$, Sílvio José Bicudo 5
}

\begin{abstract}
RESUMO
O sorgo forrageiro é uma gramínea indicada para cultivo em ambientes secos e quentes, nos quais a produtividade de outras forrageiras pode ser antieconômica. Objetivou-se, com este trabalho, estudar diferentes sistemas de manejo e diferentes velocidades de semeadura, no desenvolvimento do sorgo forrageiro cv. BRS 610. O solo da área experimental foi um Nitossolo Vermelho distroférrico. O experimento foi instalado em condições de campo, na FCA/UNESP, Campus de Botucatu-SP, utilizando-se o delineamento em blocos ao acaso, em esquema de parcela subdividida, com dezesseis tratamentos (quatro sistemas de manejo e quatro velocidades de semeadura). Os sistemas de manejo utilizados foram: semeadura direta; gradagem pesada; gradagem pesada + duas gradagens leves e escarificação. As velocidades na operação de semeadura utilizadas foram: 3, 5, 6 e $9 \mathrm{~km} \mathrm{~h}^{-1}$. Foram analisadas as seguintes variáveis: população de plantas, altura de plantas, diâmetro do colmo, massa de mil grãos e produtividades de massa verde e de massa seca. O sistema de semeadura direta foi o que proporcionou maior população de plantas, maior diâmetro do colmo e maior produção de massas verde e seca. Com o aumento da velocidade na operação de semeadura, houve redução da população de plantas e aumento do diâmetro do colmo. A velocidade de $5 \mathrm{~km} \mathrm{~h}^{-1}$ foi a que proporcionou maior produção de massas verde e seca $\left(\mathrm{kg} \mathrm{ha}^{-1}\right)$, seguida da velocidade de $3 \mathrm{~km} \mathrm{~h}^{-1}$.
\end{abstract}

Palavras-chave: Sorghum bicolor, sistemas de cultivo, características fitotécnicas.

\section{ABSTRACT \\ Effect of soil management systems and sowing speed on the development of forage sorghum}

Forage sorghum is a grass grown in dry and hot environments, where the productivity of other forages may be not economically viable. The aim of this study was to evaluate the effect of different management systems and sowing speeds on the development of forage sorghum cv. BRS 610. The soil of the experimental area was a Paleudult. The experiment was installed in field conditions, in FCA/UNESP, Botucatu Campus, using a randomized block split-plot design, with twelve treatments (four management systems and four sowing speeds). The management systems used were: no-tillage, disk harrowing + seeding; disk harrowing + two light disking + seeding; minimum tillage + seeding. The sowing speeds used were: $3,5,6$ and $9 \mathrm{~km} \mathrm{~h}^{-1}$. The following variables were analyzed: plant population, plant height, stem diameter, mass of thousand grains, green mass yield and dry mass yield. The no-tilllalge system provided the highest plant population, stem diameter, green mass yield and dry mass yield. There was a reduction in the plant population and increase in stem diameter with the increase in the sowing speed. The speed of $5 \mathrm{~km} \mathrm{~h}^{-1}$ provided the highest green and dry mass yields $\left(\mathrm{kg} \mathrm{ha}^{-1}\right)$, followed by the speed of $3 \mathrm{~km} \mathrm{~h}^{-1}$.

Key words: Sorghum bicolor, cropping systems, agronomic characteristics.

Recebido para publicação em 27/04/2012 e aprovado em 14/06/2013.

${ }^{1}$ Engenheira-Agrônoma, Doutora. Departamento de Engenharia Agrícola e Solos, Universidade Estadual do Sudoeste da Bahia, Estrada do Bem Querer, Km 4, 45083-900, Vitória da Conquista, Bahia, Brasil. flavia10meinicke@gmail.com (autora para correspondência)

${ }^{2}$ Engenheiro-Agrônomo, Doutor. Departamento de Agronomia, Associação Educacional do Vale do Jurumirim, Avenida Misael Euphrasio Leal, 347, Jardim América, 18.705050, Avaré, São Paulo, Brasil. lancarodrigues@hotmail.com

${ }^{3}$ Engenheiro-Agrônomo, Doutor. Departamento de Agronomia, Instituto Federal de Educação, Ciência e Tecnologia Baiano, Rodovia Itapetinga/Itororó, Km 2, 45.700-000, Itapetinga, Bahia, Brasil. costajf10@ hotmail.com

${ }^{4}$ Engenheiro-Agrônomo, Doutor. Departamento de Engenharia Rural, Universidade Estadual Paulista, Rua José Barbosa de Barros, 1780, Fazenda Lageado, 18.603-307, Botucatu, São Paulo, Brasil. gamero@fca.unesp.br

${ }^{5}$ Engenheiro-Agrônomo, Doutor. Departamento de Produção Vegetal, Universidade Estadual Paulista, Rua José Barbosa de Barros, 1780, Fazenda Lageado, 18.603-307, Botucatu, São Paulo, Brasil. sjbicudo@fca.unesp.br 


\section{INTRODUÇÃO}

Segundo Magalhães et al. (2003), o sorgo é uma planta $\mathrm{C} 4$ de dia curto e alta capacidade fotossintética. A grande maioria dos materiais genéticos de sorgo requer temperaturas superiores à $21^{\circ} \mathrm{C}$ para um bom crescimento e desenvolvimento. A planta de sorgo tolera mais o estresse hídrico por déficit ou por excesso do que a maioria dos outros cereais, podendo ser cultivada numa ampla faixa de condições de solo.

O cultivo do sorgo, assim como o de qualquer outra cultura inserida num sistema de rotação e, ou sucessão, necessita de condições adequadas de preparo solo, para que a cultura se estabeleça e se desenvolva normalmente.

O preparo do solo é uma operação indispensável ao bom desenvolvimento das culturas e compreende um conjunto de técnicas que, quando utilizadas racionalmente, proporcionam incremento da produtividade, mas, se mal utilizadas, podem levar à degradação dos solos em curto prazo.

A semeadura direta consiste em semear em solo não preparado previamente, diferenciando-se dos outros processos pela menor intensidade de mobilização do solo e pela redução da frequência de tráfego de máquinas sobre o terreno e, ainda, por manter sobre sua superfície grande quantidade de massa vegetal (Furlani et al. 2007).

Os efeitos de diferentes sistemas de manejo têm sido estudados por diversos autores, destacando-se os seguintes: revolvimento do solo somente nas linhas de semeadura (semeadura direta, apenas gradagens e escarificação), em vez de revolvimento total do solo (método convencional, com arações e gradagens) (Silva \& Silveira, 2002).

Possamai et al. (2001) avaliaram os efeitos dos sistemas de manejo (semeadura direta, preparo do solo com arado de aivecas, arado de discos, grade pesada e enxada rotativa), sobre as características agronômicas do milho. Observaram que o sistema de semeadura direta proporcionou aumento da população de plantas, do diâmetro do colmo, da altura de plantas, do número de espigas por hectare e da produtividade do milho.

Comparando os sistemas de manejo de solo: semeadura direta e preparo convencional (uma gradagem pesada, seguida de duas gradagens leves), na cultura do milho, Carvalho et al. (2004) encontraram menores produtividades de milho no sistema de semeadura direta, em relação às do preparo convencional do solo.

Debiasi et al. (2005), estudando o efeito da velocidade de deslocamento da semeadora na produtividade do sorgo forrageiro, verificaram que a produtividade de sementes decresceu linearmente com o aumento da velocidade.

Ao avaliar o efeito da velocidade de semeadura nas características agronômicas do milho, Fey e Santos (2000) observaram relação linear decrescente entre a velocidade média de semeadura e a população de plantas e produtividade de grãos.
Mello et al (2007), comparando diferentes velocidades de semeadura na cultura do milho, observaram que, à medida que se aumentou a velocidade de deslocamento, na operação de semeadura, houve diminuição da população de plantas e da produtividade de grãos.

Avaliando o efeito de quatro velocidades de semeadura $\left(3,6,9\right.$ e 11,2 $\left.\mathrm{km} \mathrm{h}^{-1}\right)$ nas características agronômicas da cultura do milho, Silva et al. (2000) observaram que as velocidades da semeadora-adubadora de até $6 \mathrm{~km} \mathrm{~h}^{-1}$ proporcionaram maiores estandes de plantas e número de espiga e foram responsáveis pelos maiores rendimentos de grãos.

Esta pesquisa teve como objetivo estudar diferentes sistemas de manejo e diferentes velocidades de semeadura no desenvolvimento do sorgo forrageiro cv. BRS 610.

\section{MATERIAL E MÉTODOS}

O experimento foi instalado em dezembro de 2007 e colhido em abril de 2008, na Faculdade de Ciências Agronômicas, UNESP - Botucatu, SP, nas coordenadas 22 49' Sul e $48^{\circ} 25^{\prime}$ 'Oeste, com altitude média de $786 \mathrm{~m}$, declividade variando entre 2 e $6 \%$, com exposição ao sol na face oeste. De acordo com a classificação de Köppen, o clima da região é do tipo CWa, subtropical, com verões quentes e úmidos e invernos frios e secos. A precipitação média anual é de $1400 \mathrm{~mm}$, com temperatura média do mês mais quente superior a $22^{\circ} \mathrm{C}$ e a do mês mais frio entre 3 e $18^{\circ} \mathrm{C}$.

$\mathrm{A}$ área experimental vinha sendo cultivada em sistema semeadura direta desde 1997, por meio de rotação de culturas com aveia preta e, ou, triticale (safra de inverno), soja e,ou, milho (safra de verão). Este trabalho foi conduzido sob restevas da cultura do milho, seguido de aveia preta na safra anterior. A precipitação durante o ciclo da cultura foi de $664 \mathrm{~mm}$. (Figura 1).

O solo da área experimental foi classificado como Nitossolo Vermelho distroférrico típico A moderado, textura argilosa (NVdf), em conformidade com o Sistema Brasileiro de Classificação do Solo (EMBRAPA, 2006) e apresentou 143, 351 e $506 \mathrm{~g} \mathrm{~kg}^{-1}$ de areia, silte e argila, respectivamente. A densidade das partículas e do solo foi de 3,84 e $1,30 \mathrm{~kg} \mathrm{dm}^{-3}$, respectivamente, na camada de 0 a 20 $\mathrm{cm}$ de profundidade. A análise química do solo na época do plantio apresentou: $5,8 \mathrm{pH} \mathrm{em} \mathrm{CaCl}_{2}, 28 \mathrm{mg} \mathrm{dm}^{-3} \mathrm{de} \mathrm{P}$, $2,1 \mathrm{mmol}_{\mathrm{c}} \mathrm{dm}^{-3} \mathrm{de} \mathrm{K}^{+}, 57 \mathrm{mmol}_{\mathrm{c}} \mathrm{dm}^{-3} \mathrm{de} \mathrm{Ca}^{+2}, 29 \mathrm{mmol}_{\mathrm{c}} \mathrm{dm}^{-}$

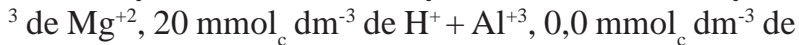
$\mathrm{Al}^{+3}$ e $81 \%$ de saturação por bases (V\%).

O experimento foi constituído de dezesseis tratamentos (quatro sistemas de manejo do solo e quatro velocidades na operação de semeadura), com quatro repetições, e delineamento experimental em blocos casualizados, seguindo-se o esquema de parcelas subdivididas.

Os tratamentos nas parcelas foram os sistemas de manejo do solo: SD (Semeadura direta); GP (Gradagem 
Pesada); GPL (Gradagem pesada + duas gradagens leves) e CR (Cultivo reduzido). Os tratamentos nas subparcelas foram as velocidades na operação de semeadura: 3, 5, 6 e $9 \mathrm{~km} \mathrm{~h}^{-1}$, velocidades aproximadas, utilizando-se as marchas A3, B2, C1 e C2 do trator, respectivamente.

Para implantação do experimento, foram utilizados os seguintes equipamentos agrícolas: trator da marca John Deere, modelo 6600 (4x2 TDA), com potência no motor de $89 \mathrm{~kW}(121 \mathrm{cv})$, utilizado nas operações de preparos do solo e semeadura do sorgo; grade de discos pesada, de arrasto, tipo off-set; grade de discos leve, de arrasto, tipo off-set; escarificador de arrasto, equipado com sete hastes parabólicas, conjugado com discos de corte e cilindro destorroador/nivelador; semeadora-adubadora de fluxo contínuo, marca SEMEATO, Modelo PHS1517, de 17 linhas, espaçadas à $0,17 \mathrm{~m}$.

Após a análise química do solo e verificação dos dados do cultivar de sorgo utilizado, realizou-se a regulagem da semeadora-adubadora, na distribuição de adubos e sementes. $\mathrm{Na}$ adubação de semeadura foram utilizados, conforme recomendação para a cultura, 300 $\mathrm{kg} \mathrm{ha}^{-1}$ da fórmula 8-28-16 ( $\mathrm{N}_{2} \mathrm{P}_{2} \mathrm{O}_{5}$ e $\left.\mathrm{K}_{2} \mathrm{O}\right)$. Na adubação de cobertura, foram aplicados $200 \mathrm{~kg} \mathrm{ha}^{-1}$ do formulado 45-0-0, aos 20 dias após a emergência do sorgo. O cultivar de sorgo utilizado foi BRS 610, com ciclo de 140 dias, apresentando pureza de $94 \%$ e poder germinativo de $90 \%$. A semeadora foi regulada para depositar as sementes à profundidade média de $30 \mathrm{~mm}$, aproximadamente, e foram gastos $12 \mathrm{~kg} \mathrm{ha}^{-1}$ de sementes, sendo a população desejada de 140 mil plantas ha ${ }^{-1}$ e o espaçamento entrelinhas de $0,17 \mathrm{~m}$.

Para determinação da velocidade média na operação de semeadura, foi utilizado um cronômetro e registrado o tempo gasto durante um percurso de $20 \mathrm{~m}$.

Para avaliar o desenvolvimento da cultura, foram analisadas as seguintes variáveis das plantas: população de plantas, altura de plantas, diâmetro do colmo, massa de mil grãos e produtividades de massa verde e de massa seca. A população de plantas de sorgo foi avaliada pela contagem das plantas presentes em duas linhas, na distância de dez metros. Para determinação da altura de plantas, foram medidas, nas três linhas centrais, dez plantas no final do ciclo e considerada a distância do solo até a inserção da folha bandeira. $\mathrm{O}$ diâmetro do colmo foi medido no final do ciclo, com paquímetro, no primeiro internó acima do solo, nas três linhas centrais, utilizando-se dez plantas. Para determinação da massa de mil grãos, realizou-se a contagem de 100 grãos, sendo, posteriormente, transformados para 1000 grãos e tendo a massa ajustada para $13 \%$ do teor de umidade. A colheita manual das plantas do sorgo, no ponto de ensilagem, foi realizada nas duas linhas centrais, numa distância de 20 metros, em uma área útil de $6,8 \mathrm{~m}^{2}$. Após a colheita e pesagem, as plantas foram secadas em estufa elétrica, a $65^{\circ} \mathrm{C}$, até atingir massa constante, para determinação da massa seca.

Após a análise de variância os dados foram comparados pelo teste de Tukey, a 5\% de probabilidade, utilizando-se do programa SISVAR (Ferreira, 2011).

\section{RESULTADOS E DISCUSSÃO}

Analisando-se os valores médios da população de plantas, entre os diferentes sistemas de manejo, observa-se pelo teste de Tukey, a 5\% de probabilidade, que houve diferença significativa entre as médias (Tabela 1). O tratamento SD apresentou menor valor e diferiu estatisticamente do tratamento GPL, com uma redução de $16,88 \%$ da população final. Os tratamentos GP e CR apresentaram valores intermediários e não diferiram dos tratamentos SD e GPL.

Comparando-se os sistemas de manejo, dentro de cada velocidade, observa-se que, na velocidade de $5 \mathrm{~km} \mathrm{~h}^{-1}$, o tratamento GPL promoveu maior população de plantas e

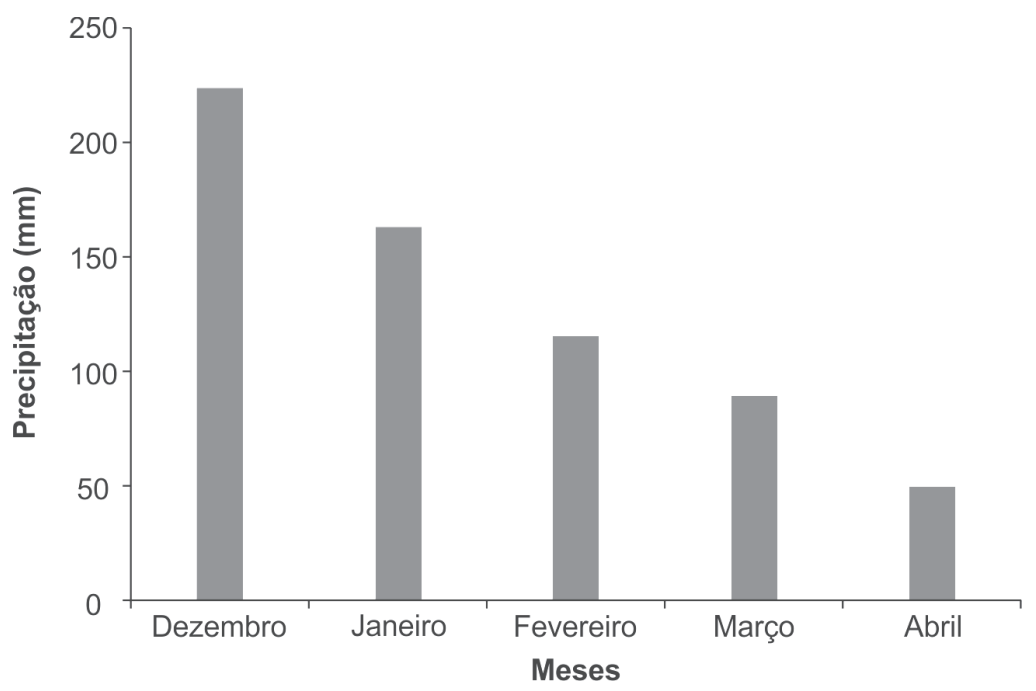

Figura 1. Precipitação média mensal, durante o ciclo da cultura, no ano 2007/2008.

Rev. Ceres, Viçosa, v. 61, n.3, p. 332-337, mai/jun, 2014 
diferenciou-se estatisticamente dos tratamentos SD e GP. $\mathrm{Na}$ velocidade de $6 \mathrm{~km} \mathrm{~h}^{-1}$, o tratamento GPL apresentou maior população de plantas e diferenciou-se estatisticamente dos tratamentos SD e CR. Nas velocidades de 3 a 9 $\mathrm{km} \mathrm{h}^{-1,}$ não foram observadas diferenças significativas entre os sistemas de manejo (Tabela 1).

Na Tabela 1, observa-se que o aumento nas velocidades de semeadura reduziu os valores médios da população de plantas, concordando com os valores obtidos por Mello et al (2007), Garcia et al. (2006), Mahl (2006), Silva et al. (2000) e Fey \& Santos (2000).

A utilização de semeadoras em altas velocidades pode abrir sulcos maiores, revolver faixas mais largas e dificultar a compressão do solo com a semente pela roda compactadora, comprometendo a germinação, a emergência das sementes e, consequentemente, a população de plantas.

Comparando-se a altura de plantas, verifica-se que não houve significância pelo teste Tukey, a 5\% de probabilidade, tanto para os sistemas de manejo quanto para as velocidades na operação de semeadura (Tabela 2). Estes dados estão em concordância com os dados obtidos por Ribas (2004), pesquisando o sorgo forrageiro.

Analisando-se os valores médios do diâmetro do colmo, entre os sistemas de manejo, observa-se que não houve efeito significativo pelo teste de Tukey, a $5 \%$ de probabilidade (Tabela 3 ). Comparando-se os sistemas de manejo dentro de cada velocidade na operação de semeadura, observa-se que o tratamento SD foi o que apresentou maior diâmetro do colmo, diferindo do tratamento GPL, na velocidade de $3 \mathrm{~km} \mathrm{~h}^{-1}$. Na velocidade de $9 \mathrm{~km} \mathrm{~h}^{-1}$, o tratamento SD foi o que apresentou maior diâmetro do colmo, diferindo dos tratamentos GP e GPL (Tabela 3). Esse fato pode estar relacionado com a menor população de plantas, encontradas nesse tratamento.

Com relação aos valores médios das velocidades na operação de semeadura (Tabela 3), observa-se que a maior velocidade $\left(9 \mathrm{~km} \mathrm{~h}^{-1}\right)$ proporcionou os maiores valores para diâmetro do colmo, mas diferenciou-se, nesse aspecto, apenas da menor velocidade $\left(3 \mathrm{~km} \mathrm{~h}^{-1}\right)$. Isto ocorreu por ter havido menor crescimento populacional de plantas, na maior velocidade, o que favoreceu menor competição entre plantas.

Na Tabela 4, são apresentados os valores da massa de mil grãos, em função dos sistemas de manejo e das velocidades de semeadura. Verifica-se que não houve diferença significativa entre as médias dos sistemas de manejo.

Comparando-se os valores médios das velocidades na operação de semeadura, notou-se que a velocidade de $9 \mathrm{~km} \mathrm{~h}^{-1}$ foi a que proporcionou maior massa de mil grãos e diferenciou-se estaticamente, apenas da velocidade de $3 \mathrm{~km} \mathrm{~h}^{-1}$.

Nas Tabelas 5 e 6, encontram-se os valores médios de produtividade de massas verde e seca $\left(\mathrm{kg} \mathrm{ha}^{-1}\right)$. Foram observadas diferenças significativas entre os sistemas de

Tabela 1. População de plantas $\left(\mathrm{n}^{\circ}\right.$ de plantas $\left.h^{-1}\right)$ em função dos sistemas de manejo e velocidades na operação de semeadura

\begin{tabular}{lccccc}
\hline Sistemas & \multicolumn{5}{c}{ Velocidades na operação de semeadura $\left(\mathbf{k m ~ \mathbf { h } ^ { - 1 } )}\right.$} \\
\cline { 2 - 6 } de manejo & $\mathbf{3}$ & $\mathbf{5}$ & $\mathbf{6}$ & $\mathbf{9}$ & Médias \\
\hline SD & $142.678 \mathrm{aA}$ & $132.142 \mathrm{bB}$ & $128.571 \mathrm{cBC}$ & $122.499 \mathrm{aC}$ & $131.472 \mathrm{~b}$ \\
$\mathrm{GP}$ & $143.928 \mathrm{aA}$ & $133.750 \mathrm{bB}$ & $134.642 \mathrm{abB}$ & $121.785 \mathrm{aC}$ & $133.526 \mathrm{ab}$ \\
$\mathrm{CR}$ & $147.857 \mathrm{aA}$ & $137.500 \mathrm{abB}$ & $129.470 \mathrm{bBC}$ & $122.752 \mathrm{aC}$ & $134.395 \mathrm{ab}$ \\
$\mathrm{GPL}$ & $148.571 \mathrm{aA}$ & $141.428 \mathrm{aAB}$ & $137.500 \mathrm{aB}$ & $124.107 \mathrm{aC}$ & $137.901 \mathrm{a}$ \\
\hline Médias & $145.759 \mathrm{~A}$ & $136.205 \mathrm{~B}$ & $132.546 \mathrm{~B}$ & $122.786 \mathrm{C}$ & \\
\hline
\end{tabular}

DMS médias $=5.777,28 ;$ DMS interação $=7.603,47 ;$ CV sistemas de manejo $(\%)=15,24 ;$ CV velocidades na operação de semeadura $(\%)$ $=11,63 . \mathrm{SD}=$ Semeadura direta; $\mathrm{GP}=$ Grade pesada + semeadura GPL $=$ Grade pesada + duas gradagens leves + semeadura; $\mathrm{CR}=$ Escarificação + semeadura. Médias seguidas pela mesma letra, minúscula na coluna e maiúscula na linha, não diferiram entre si pelo teste de Tukey a $5 \%$ de probabilidade.

Tabela 2. Altura de plantas ( $\mathrm{cm}$ ) em função dos sistemas de manejo e velocidades na operação de semeadura

\begin{tabular}{lccccc}
\hline Sistemas & \multicolumn{5}{c}{ Velocidades na operação de semeadura $\left(\mathbf{k m ~ \mathbf { h } ^ { - 1 } )}\right.$} \\
\cline { 2 - 6 } de manejo & $\mathbf{3}$ & $\mathbf{5}$ & $\mathbf{6}$ & $\mathbf{9}$ & Médias \\
\hline SD & $195,25 \mathrm{aA}$ & $188,51 \mathrm{aA}$ & $195,19 \mathrm{aA}$ & $188,89 \mathrm{aA}$ & $191,96 \mathrm{a}$ \\
$\mathrm{GP}$ & $194,69 \mathrm{aA}$ & $187,64 \mathrm{aA}$ & $191,63 \mathrm{aA}$ & $181,81 \mathrm{aA}$ & $188,94 \mathrm{a}$ \\
$\mathrm{CR}$ & $195,88 \mathrm{aA}$ & $188,56 \mathrm{aA}$ & $187,25 \mathrm{aA}$ & $182,07 \mathrm{aA}$ & $188,44 \mathrm{a}$ \\
GPL & $195,25 \mathrm{aA}$ & $188,86 \mathrm{aA}$ & $194,17 \mathrm{aA}$ & $192,31 \mathrm{aA}$ & $192,65 \mathrm{a}$ \\
\hline Médias & $195,26 \mathrm{~A}$ & $188,39 \mathrm{~A}$ & $192,06 \mathrm{~A}$ & $186,27 \mathrm{~A}$ &
\end{tabular}

DMS médias = 10,68; DMS interação $=19,27 ;$ CV sistemas de manejo $(\%)=6,86 ;$ CV velocidades na operação de semeadura $(\%)=7,17$. $\mathrm{SD}=$ Semeadura direta; GP = Grade pesada + semeadura; GPL = Grade pesada + duas gradagens leves + semeadura; CR $=$ Escarificação + semeadura. Médias seguidas pela mesma letra, minúscula na coluna e maiúscula na linha, não diferiram entre si pelo teste de Tukey a $5 \%$ de probabilidade. 
manejo, sendo que a maior produtividade foi obtida no tratamento de SD, que, porém, não se diferenciou estatisticamente do tratamento GP.

A maior produtividade de massas verde e seca $(\mathrm{kg}$ $\mathrm{ha}^{-1}$ ), obtida no tratamento de SD, deve-se ao fato de esse sistema manter a umidade do solo por meio da cobertura residual, por mais tempo do que os outros sistemas de manejo. Assim, na época de baixa pluviosidade, que coincide com a fase final do desenvolvimento do sorgo forrageiro, o sistema de semeadura direta diminui a evaporação e mantém maior umidade do solo, favorecendo o desenvolvimento da cultura.

Analisando-se os valores médios das velocidades, na Tabela 5, verifica-se que houve diferença significativa entre os valores médios de produtividade de massa verde $\left(\mathrm{kg} \mathrm{ha}^{-1}\right)$. As velocidades de 5 e $9 \mathrm{~km} \mathrm{~h}^{-1}$ foram as que promoveram maior e menor produtividade de massa verde do sorgo, respectivamente.

Com relação à massa seca do sorgo, a velocidade de 5 $\mathrm{km} \mathrm{h}^{-1}$ foi a que promoveu maior produtividade, mas não se diferenciou estatisticamente da velocidade de $3 \mathrm{~km} \mathrm{~h}^{-1}$. A maior velocidade, $9 \mathrm{~km} \mathrm{~h}^{-1}$, proporcionou a menor produtividade de massa seca, mas não se diferenciou da velocidade intermediária (Tabela 6).

A maior produtividade de massa seca encontrada nas menores velocidades está de acordo com os dados apresentados por Debiasi et al. (2005), estudando o efeito de diferentes velocidades de deslocamento da semeadora na produtividade do sorgo forrageiro, e por Fey e Santos (2000), na cultura do milho.

Tabela 3. Diâmetro do colmo de plantas (cm) em função dos sistemas de manejo e velocidades na operação de semeadura

\begin{tabular}{lllllc}
\hline Sistemas & \multicolumn{5}{c}{ Velocidades na operação de semeadura $\left(\mathbf{k m ~ h}^{\mathbf{1}}\right)$} \\
\cline { 2 - 5 } de manejo & $\mathbf{3}$ & $\mathbf{5}$ & $\mathbf{6}$ & $\mathbf{9}$ & Médias \\
\hline $\mathrm{SD}$ & $2,00 \mathrm{abB}$ & $2,21 \mathrm{aB}$ & $2,35 \mathrm{aAB}$ & $2,76 \mathrm{aA}$ & $2,33 \mathrm{a}$ \\
$\mathrm{GP}$ & $2,14 \mathrm{aA}$ & $2,14 \mathrm{aA}$ & $2,13 \mathrm{aA}$ & $2,24 \mathrm{bA}$ & $2,16 \mathrm{a}$ \\
$\mathrm{CR}$ & $2,02 \mathrm{abA}$ & $2,19 \mathrm{aA}$ & $2,29 \mathrm{aA}$ & $2,34 \mathrm{abA}$ & $2,21 \mathrm{a}$ \\
$\mathrm{GPL}$ & $1,71 \mathrm{bB}$ & $2,07 \mathrm{aAB}$ & $2,02 \mathrm{aAB}$ & $2,25 \mathrm{bA}$ & $2,01 \mathrm{a}$ \\
\hline Médias & $1,96 \mathrm{~B}$ & $2,15 \mathrm{AB}$ & $2,19 \mathrm{AB}$ & $2,39 \mathrm{~A}$ &
\end{tabular}

DMS médias $=0,43 ;$ DMS interação $=0,46 ; \mathrm{CV}$ sistemas de manejo $(\%)=17,76 ; \mathrm{CV}$ velocidades na operação de semeadura $(\%)=11,02$. $\mathrm{SD}=$ Semeadura direta; GP $=$ Grade pesada + semeadura; GPL $=$ Grade pesada + duas gradagens leves + semeadura; CR = Escarificação + semeadura. Médias seguidas pela mesma letra, minúscula na coluna e maiúscula na linha, não diferiram entre si pelo teste de Tukey a 5\% de probabilidade.

Tabela 4. Massa de mil grãos (g) em função dos sistemas de manejo e velocidades na operação de semeadura

\begin{tabular}{llllll}
\hline Sistemas & \multicolumn{5}{c}{ Velocidades na operação de semeadura $\left(\mathbf{k m} \mathbf{h}^{\mathbf{1}}\right)$} \\
\cline { 2 - 5 } de manejo & $\mathbf{3}$ & $\mathbf{5}$ & $\mathbf{6}$ & $\mathbf{9}$ & Médias \\
\hline SD & $70,44 \mathrm{aA}$ & $69,45 \mathrm{aA}$ & $71,67 \mathrm{aA}$ & $77,31 \mathrm{aA}$ & $72,22 \mathrm{a}$ \\
$\mathrm{GP}$ & $71,44 \mathrm{aA}$ & $71,32 \mathrm{aA}$ & $72,46 \mathrm{aA}$ & $71,69 \mathrm{aA}$ & $71,73 \mathrm{a}$ \\
$\mathrm{CR}$ & $65,65 \mathrm{abB}$ & $67,99 \mathrm{aB}$ & $71,46 \mathrm{aAB}$ & $77,78 \mathrm{aA}$ & $70,72 \mathrm{a}$ \\
GPL & $60,35 \mathrm{bB}$ & $66,89 \mathrm{aB}$ & $69,49 \mathrm{aAB}$ & $75,71 \mathrm{aA}$ & $68,11 \mathrm{a}$ \\
\hline Médias & $66,97 \mathrm{~B}$ & $68,91 \mathrm{AB}$ & $71,27 \mathrm{AB}$ & $75,62 \mathrm{~A}$ & \\
\hline
\end{tabular}

DMS médias: 6,35; DMS interação: 9,79; CV sistemas de manejo $(\%)=12,27 ; \mathrm{CV}$ velocidades na operação de semeadura $(\%)=9,99$. SD $=$ Semeadura direta; $\mathrm{GP}=$ Grade pesada + semeadura; $\mathrm{GPL}=$ Grade pesada + duas gradagens leves + semeadura; $\mathrm{CR}=$ Escarificação + semeadura. Médias seguidas pela mesma letra, minúscula na coluna e maiúscula na linha, não diferiram entre si pelo teste de Tukey a 5\% de probabilidade.

Tabela 5. Valores médios de produtividade de massa verde do sorgo $\left(\mathrm{kg} \mathrm{ha}^{-1}\right)$ em função dos sistemas de manejo e das velocidades na operação de semeadura

\begin{tabular}{llllll}
\hline Sistemas & \multicolumn{5}{c}{ Velocidades na operação de semeadura $\left(\mathbf{k m ~ h}^{\mathbf{1}}\right)$} \\
\cline { 2 - 6 } de manejo & $\mathbf{3}$ & $\mathbf{5}$ & $\mathbf{6}$ & $\mathbf{9}$ & Médias \\
\hline SD & $51.309 \mathrm{aA}$ & $51.371 \mathrm{aA}$ & $51.321 \mathrm{aA}$ & $51.244 \mathrm{aA}$ & $51.311 \mathrm{a}$ \\
$\mathrm{GP}$ & $51.260 \mathrm{aA}$ & $51.294 \mathrm{abA}$ & $51.143 \mathrm{bAB}$ & $51.033 \mathrm{bB}$ & $51.145 \mathrm{ab}$ \\
$\mathrm{CR}$ & $51.172 \mathrm{abA}$ & $51.156 \mathrm{bcA}$ & $49.059 \mathrm{cB}$ & $48.099 \mathrm{bC}$ & $49.872 \mathrm{c}$ \\
$\mathrm{GPL}$ & $50.068 \mathrm{bB}$ & $51.126 \mathrm{cA}$ & $51.054 \mathrm{bcA}$ & $49.006 \mathrm{bC}$ & $50.314 \mathrm{~b}$ \\
\hline Médias & $50.952 \mathrm{~B}$ & $51.217 \mathrm{~A}$ & $50.644 \mathrm{C}$ & $49.845 \mathrm{D}$ &
\end{tabular}

DMS médias = 141,74; DMS interação: 166,66 ; CV sistemas de manejo $(\%)=11,21$; CV velocidades na operação de semeadura $(\%)=7,64$. $\mathrm{SD}=$ Semeadura direta GP $=$ Grade pesada + semeadura GPL $=$ Grade pesada + duas gradagens leves + semeadura; CR $=$ Escarificação + semeadura. Médias seguidas pela mesma letra, minúscula na coluna e maiúscula na linha, não diferiram entre si pelo teste de Tukey a 5\% de probabilidade.

Rev. Ceres, Viçosa, v. 61, n.3, p. 332-337, mai/jun, 2014 
Tabela 6. Valores médios de produtividade de massa seca do sorgo $\left(\mathrm{kg} \mathrm{ha}^{-1}\right)$ em função dos sistemas de manejo e das velocidades na operação de semeadura

\begin{tabular}{llllll}
\hline Sistemas & \multicolumn{5}{c}{ Velocidades na operação de semeadura $\left(\mathbf{k m ~ h} \mathbf{h}^{-\mathbf{1}}\right)$} \\
\cline { 2 - 6 } de manejo & $\mathbf{3}$ & $\mathbf{5}$ & $\mathbf{6}$ & $\mathbf{9}$ & Médias \\
\hline $\mathrm{SD}$ & $16.309 \mathrm{aA}$ & $16.371 \mathrm{aA}$ & $16.321 \mathrm{aA}$ & $16.244 \mathrm{aA}$ & $16.311 \mathrm{a}$ \\
$\mathrm{GP}$ & $16.260 \mathrm{aB}$ & $16.294 \mathrm{abA}$ & $16.143 \mathrm{bA}$ & $16.033 \mathrm{bB}$ & $16.183 \mathrm{ab}$ \\
$\mathrm{CR}$ & $16.172 \mathrm{abA}$ & $16.156 \mathrm{~b} \mathrm{~A}$ & $15.959 \mathrm{cB}$ & $15.899 \mathrm{bB}$ & $16.047 \mathrm{bc}$ \\
$\mathrm{GPL}$ & $16.068 \mathrm{bAB}$ & $16.126 \mathrm{cA}$ & $16.054 \mathrm{bcAB}$ & $15.906 \mathrm{bB}$ & $16.039 \mathrm{c}$ \\
\hline Médias & $16.202 \mathrm{AB}$ & $16.263 \mathrm{~A}$ & $16.119 \mathrm{BC}$ & $16.020 \mathrm{C}$ &
\end{tabular}

DMS médias $=141,70 ;$ DMS interação $=166,58 ;$ CV sistemas de manejo $(\%)=11,21 ;$ CV velocidades na operação de semeadura $(\%)=7,64$. $\mathrm{SD}=$ Semeadura direta; GP = Grade pesada + semeadura; GPL = Grade pesada + duas gradagens leves + semeadura; $\mathrm{CR}=$ Escarificação + semeadura. Médias seguidas pela mesma letra, minúscula na coluna e maiúscula na linha, não diferiram entre si pelo teste de Tukey a $5 \%$ de probabilidade.

\section{CONCLUSÕES}

O tratamento SD foi o que proporcionou maior população de plantas e maior diâmetro do colmo e os tratamentos CR e GPL, os que proporcionaram menores produtividades de massas verde e seca do sorgo $\left(\mathrm{kg} \mathrm{ha}^{-1}\right)$.

Com o aumento da velocidade de semeadura, houve redução da população de plantas e aumento dos valores do diâmetro do colmo e das massas verde e seca da parte aérea por planta.

A velocidade de $5 \mathrm{~km} \mathrm{~h}^{-1}$, foi a que proporcionou maior produtividade de massas verde e seca $\left(\mathrm{kg} \mathrm{ha}^{-1}\right)$, seguida da velocidade de $3 \mathrm{~km} \mathrm{~h}^{-1}$.

\section{REFERÊNCIAS}

Carvalho MD, Soratto RP, Athayde MLF, Arf O \& Sá ME. (2004). Produtividade do milho em sucessão a adubos verdes no sistema de plantio direto e convencional. Pesquisa Agropecuária Brasileira, 39, 47-53.

Debiasi H, Martins J D \& Missio EL (2005) Efeito de deslocamento da semeadora e do tipo de disco dosador de sementes no estabelecimento e produtividade do sorgo forrageiro (Sorghum bicolor L. Moench). Pesq. Agrop. Gaúcha, 11:23-30.

Empresa Brasileira de Pesquisa Agropecuária - EMBRAPA (2006) Centro Nacional de Pesquisa de Solos. Sistema brasileiro de classificação de solos. $2^{\mathrm{a}}$ ed. $306 \mathrm{p}$.

Ferreira, DF (2011) Sisvar: a computer statistical analysis system. Ciência e Agrotecnologia (UFLA), 35:1039-1042.

Fey E \& Santos SR (2000) Efeito da velocidade de semeadura sobre a população de plantas, distribuição longitudinal e produção de grãos de milho (Zea mays L.). In: $29^{\circ}$ Congresso Brasileiro de Engenharia Agrícola, Fortaleza. Anais, Sociedade Brasileira de Engenharia Agrícola. CD-ROM.

Furlani CE, Pavan Júnior A, Lopes A, Silva RP, Grotta DCC \& Cortez JW (2007). Desempenho operacional de semeaduraadubadora em diferentes manejos da cobertura e da velocidade. Engenharia Agrícola. 27:456-462.

Garcia LC, Jasper R, Jasper M, Fornari AJ \& Blum J (2006) Influência da velocidade de deslocamento na semeadura do milho. Engenharia Agrícola, 26:520-527.

Magalhães PC, Durães FOM \& Rodrigues JAS (2003) Fisiologia da planta de sorgo. Sete Lagoas, EMBRAPA Milho e Sorgo. 4p. (Boletim técnico, 87).
Mahl D (2006) Desempenho operacional de semeadora em função de mecanismos de corte, velocidade e solos, no sistema plantio direto do milho. Tese de Doutorado. Universidade Estadual Paulista, Botucatu. 143p.

Mello AJR, Furlani C.E.A, Silva RP, Lopes A \& Borsatto EA (2007) Produtividade de híbridos de milho em função da velocidade de semeadura. Engenharia Agrícola, 27:479-486.

Possamai JM, Souza CM \& Galvão JCC (2001) Sistemas de preparo do solo para o cultivo do milho safrinha. Bragantia, 60:79-82.

Ribas PM (2004) Sistema de produção 2. Sete Lagoas, Embrapa Milho e Sorgo. Sem paginação. (Boletim técnico).

Silva CC \& Silveira PM (2002) Influências de sistemas agrícolas em características químico-físicas do solo. Ciência Agrotécnica, 26:505-515.

Silva JG, Kluthcouski J \& Silveira PM (2000) Desempenho de uma semeadora-adubadora no estabelecimento e na produtividade da cultura do milho sob plantio direto. Scientia Agrícola, 57:7-12. 